Wolfram Reichenbecher · Bodo Philipp •

Marc J.-F. Suter · Bernhard Schink

\title{
Hydroxyhydroquinone reductase, the initial enzyme involved in the degradation of hydroxyhydroquinone (1,2,4-trihydroxybenzene) by Desulfovibrio inopinatus
}

Received: 13 August 1999 Revised: 19 November 1999 / Accepted: 22 November 1999 / Published online: 18 January 2000

(C) Springer-Verlag 2000

\begin{abstract}
The recently isolated sulfate reducer Desulfovibrio inopinatus oxidizes hydroxyhydroquinone $(1,2,4-$ trihydroxybenzene; $\mathrm{HHQ}$ ) to $2 \mathrm{~mol}$ acetate and $2 \mathrm{~mol} \mathrm{CO}_{2}$ (mol substrate) $)^{-1}$, with stoichiometric reduction of sulfate to sulfide. None of the key enzymes of fermentative HHQ degradation, i.e. HHQ-1,2,3,5-tetrahydroxybenzene transhydroxylase or phloroglucinol reductase, were detected in cell-free extracts of $D$. inopinatus, indicating that this bacterium uses a different pathway for anaerobic HHQ degradation. HHQ was reduced with NADH in cell-free extracts to a nonaromatic compound, which was identified as dihydrohydroxyhydroquinone by its retention time in HPLC separation and by HPLC-mass spectrometry. The compound was identical with the product of chemical reduction of HHQ with sodium borohydride. Dihydrohydroxyhydroquinone was converted stoichiometrically to acetate and to an unknown coproduct. HHQ reduction was an enzymatic activity which was present in the cellfree extract at $0.25-0.30 \mathrm{U}(\mathrm{mg} \text { protein })^{-1}$, with a $\mathrm{pH}$ optimum at 7.5. The enzyme was sensitive to sodium chloride, potassium chloride, EDTA, and $o$-phenanthroline, and exhibited little sensitivity towards sulfhydryl group reagents, such as copper chloride or $p$-chloromercuribenzoate.
\end{abstract}

Key words Trihydroxybenzenes .

Hydroxyhydroquinone $\cdot$ Phloroglucinol $\cdot$ Reductive dearomatization $\cdot$ Desulfovibrio sp.

W. Reichenbecher · B. Philipp · B. Schink (困)

Fakultät für Biologie, Universität Konstanz, Postfach 5560,

D-78457 Konstanz, Germany

e-mail: Bernhard.Schink@uni-konstanz.de,

Tel.: +49-7531-882140, Fax: +49-7531-882966

M. J.-F. Suter

Department of Chemistry, EAWAG, Überlandstrasse 133, CH-8600 Dübendorf, Switzerland

\section{Introduction}

Hydroxyhydroquinone (1,2,4-trihydroxybenzene; HHQ) is an intermediary product in the aerobic degradation of hydroxylated aromatic compounds such as phloroglucinol, resorcinol, resorcylic acid, $p$-hydroxybenzoate, phenol, and dibenzo dioxin (Chapman and Ribbons 1976; Karasevich et al. 1976; Patel et al. 1990; Stolz and Knackmuss 1993; Armengaud et al. 1999). In some microorganisms, oxygenases have been found which form maleylacetate from HHQ, which is further reduced to 3-oxoadipate. The pathway is known as the HHQ variation of the pathway that usually involves catechol as intermediate (Middelhoven 1993).

In the absence of molecular oxygen, trihydroxybenzenes are degraded by fermenting bacteria such as Eubacterium oxidoreducens, Pelobacter acidigallici, Pelobacter massiliensis, and the homoacetogenic Holophaga foetida through the phloroglucinol pathway (Schink and Pfennig 1982; Krumholz et al. 1987; Brune and Schink 1990; Schnell et al. 1991; Kreft and Schink 1993). One or three transhydroxylation reactions transform pyrogallol $(1,2,3$ trihydroxybenzene) or HHQ to phloroglucinol (1,3,5-trihydroxybenzene; Brune and Schink 1990; Brune et al. 1992), which is subsequently reduced to dihydrophloroglucinol (Samain et al. 1986; Haddock and Ferry 1989; Brune and Schink 1992) and further oxidized to three acetate residues.

Reductive steps are common reactions for the destabilization of aromatic compounds (Schink et al. 1992; Heider and Fuchs 1997). With benzoyl-CoA, reductive dearomatization requires electrons at very low redox potential and ATP as an additional energy source to overcome the mesomery energy barrier (Boll et al. 1997). In resorcinol (1,3-dihydroxybenzene) reduction by fermenting bacteria, the electron donor has not yet been identified; the reaction is measured in vitro with low-potential electron donors such as benzyl viologen (Kluge et al. 1990; Schüler and Schink, unpublished data). Reductive dearomatization of phloroglucinol to dihydrophloroglucinol is catalyzed by an NADPH-dependent enzyme. 
Recently, we isolated a novel sulfate-reducing bacterium, Desulfovibrio inopinatus, with HHQ as sole organic substrate in the presence of sulfate (Reichenbecher and Schink 1997). This bacterium does not contain phloroglucinol reductase or any transhydroxylating activity. In the present communication, we describe a new reductive dearomatization reaction in $D$. inopinatus which reduces HHQ to dihydrohydroxyhydroquinone. This enzyme differs substantially from the phloroglucinol reductases of $E$. oxidoreducens (Haddock and Ferry 1989), P. acidigallici (Brune and Schink 1992), and P. massiliensis (Brune et al. 1992).

\section{Materials and methods}

Source of strain and growth conditions

Desulfovibrio inopinatus strain HHQ20 (DSM 10711) was described in detail earlier (Reichenbecher and Schink 1997) and was taken from our own culture collection. The strain was cultivated in a bicarbonate-buffered, sulfide-reduced anoxic mineral medium with $1 \%$ salinity and $20 \mathrm{mM}$ sulfate (Widdel and Pfennig 1981). The medium was dispensed in 50-ml serum bottles sealed with butyl rubber stoppers, or in 1-1 infusion bottles sealed with rubber septa with a $\mathrm{N}_{2} / \mathrm{CO}_{2}(90: 10 \mathrm{v} / \mathrm{v})$ headspace. Substrates were added from concentrated stock solutions. Solutions of oxygen-sensitive compounds were prepared anoxically and sterilized by filtration. Purity was checked microscopically in cultures grown in mineral media with $2 \mathrm{mM}$ HHQ and in media containing $0.05 \%(\mathrm{w} / \mathrm{v})$ yeast extract, $5 \mathrm{mM}$ glucose, and $5 \mathrm{mM}$ fumarate.

Enzyme assays in cell-free extracts

Cells of a 1-1 culture in the late exponential growth phase were harvested in an anoxic chamber (Coy, Ann Arbor, Mich., USA) with an $\mathrm{N}_{2} / \mathrm{H}_{2}$ atmosphere $(95: 5 \mathrm{v} / \mathrm{v})$, centrifuged at $13,000 \times g$ for $20 \mathrm{~min}$, and washed with $250 \mathrm{ml}$ anoxic $100 \mathrm{mM}$ potassium phosphate buffer, $\mathrm{pH}$ 7.0. Extracts were prepared anoxically by passing resuspended cells twice through a French press cell at $138 \mathrm{MPa}$. Cell debris was removed by centrifugation at $20,000 \times g$ for $20 \mathrm{~min}$. This preparation is subsequently referred to as the cell-free extract. The cytoplasmic and membrane fractions were separated by ultracentrifugation at $160,000 \times g$ for $30 \mathrm{~min}$.

A six-fold enriched HHQ reductase preparation was obtained by passing a $160,000 \times g$ supernatant fraction over a HiTrap Q anion exchange column and eluting with a linear $\mathrm{NaCl}$ gradient $(0-500 \mathrm{mM})$.

Enzyme activities were measured anoxically at $25^{\circ} \mathrm{C}$, either discontinuously by HPLC or continuously by photometry. In routine tests, reduction of HHQ with NADH was measured photometrically as the decrease in NADH at $365 \mathrm{~nm}$ wavelength in oxygenfree $100 \mathrm{mM}$ potassium phosphate buffer, $\mathrm{pH} 7.0$, in the presence of $0.2 \mathrm{mM}$ dithioerythritol. Protein was quantified with bovine serum albumin as standard (Bradford 1976).

Degradation of HHQ and formation of the product was monitored discontinuously by HPLC analysis. The assay was performed under strictly anoxic conditions. An assay mixture used for HPLC-MS analysis contained $50 \mathrm{mM}$ potassium phosphate buffer (pH 7.0), $0.3 \mathrm{mM} \mathrm{NADH}$, and $100 \mu \mathrm{l}$ cell-free extract $(0.4-0.5 \mathrm{mg}$ protein) and was started by the addition of $1 \mathrm{mM}$ HHQ. Samples $(100 \mu \mathrm{l})$ were taken from the reaction mixture at regular intervals and immediately transferred to $400 \mu \mathrm{l}$ phosphoric acid (100 $\mathrm{mM})$ in order to stop all biological activities.
HPLC analysis

Aromatic compounds and $\mathrm{NAD}(\mathrm{H})$ were routinely analyzed by HPLC equipped with a $\mathrm{C}_{18}$ reversed phase column (Grom, Herrenberg, Germany), a UV detector and an autosampler (Brune and Schink 1990). For separation of HHQ and the reduction product dihydrohydroxyhydroquinone, a gradient with ammonium acetate buffer (10 mM, pH 3.8 adjusted with acetic acid) as eluent $\mathrm{A}$ and methanol as eluent B was used. One separation run took $8 \mathrm{~min}$ and started with $10 \%$ B. Eluent B was increased at $0.5 \mathrm{~min}$ to $20 \%$ within $0.3 \mathrm{~min}$, at $1.5 \mathrm{~min}$ to $35 \%$ within $3.4 \mathrm{~min}$, and was decreased to $10 \%$ at $6.0 \mathrm{~min}$ within $0.2 \mathrm{~min}$. The flow rate was $1 \mathrm{ml}$ $\mathrm{min}^{-1}$ and the detection wavelengths were $206 \mathrm{~nm}$ and $260 \mathrm{~nm}$. UV/VIS on-line scans were acquired with a Beckman 168 diodearray detector. Alternatively, HHQ reductase reaction products were analyzed by HPLC ion exchange chromatography. The HPX 87-H-ion exchange column from Biorad (Munich, Germany) was eluted with $5 \mathrm{mM}$ sulfuric acid at $0.6 \mathrm{ml} \mathrm{min}-1$ and connected to a refraction index detector. With this method, acetate and an unidentified product eluting at $31 \mathrm{~min}$ were separated.

\section{HPLC/mass spectroscopy}

Mass spectra were acquired on a Platform LC (Micromass, Manchester, UK), using negative ion electrospray. The needle voltage was set to $3.75 \mathrm{kV}$, the cone voltage to $26 \mathrm{~V}$, giving soft ionization conditions. Nitrogen gas was used as nebulizer and drying gas $\left(150^{\circ} \mathrm{C}\right)$. The mass spectrum was scanned from 90 to $130 \mathrm{Da}$ at one scan per second. HPLC analysis was performed under the same conditions as described above for separation of HHQ and its reduction product, using a Hewlett Packard 1100 system.

\section{Chemical reduction of HHQ}

For chemical reduction of HHQ, $2.5 \mathrm{ml}$ of freshly and anoxically prepared $10 \mathrm{mM} \mathrm{NaBH}_{4}$ was added dropwise to $500 \mu \mathrm{l}$ of $50 \mathrm{mM}$ HHQ within $10 \mathrm{~min}$ while stirring. The reaction was performed under strictly anoxic conditions in a 5-ml serum bottle sealed with a butyl rubber stopper, and the reaction mixture was incubated at room temperature for 3-4 h. HHQ reduction and product formation were monitored discontinuously as described above for the HHQ reductase assay.

\section{Chemicals}

All chemicals were of analytical or reagent grade quality and were obtained from Biomol (Ilvesheim, Germany), Boehringer (Mannheim, Germany), Eastman Kodak (Rochester, NY), Fluka (NeuUlm, Germany), Merck (Darmstadt, Germany), Pharmacia (Freiburg, Germany), Serva (Heidelberg, Germany), and Sigma (Deisenhofen, Germany). Gases were purchased from Messer-Griesheim (Darmstadt, Germany), and Sauerstoffwerke Friedrichshafen (Friedrichshafen, Germany).

\section{Results}

\section{Reduction of HHQ}

Cell-free extract of $D$. inopinatus does not contain phloroglucinol reductase or HHQ: 1,2,3,5-tetrahydroxybenzene transhydroxylase activity (Reichenbecher and Schink 1997). Instead, cell-free extracts $(20,000 \times g$ supernatant $)$ contained a HHQ reductase activity that used NADH as electron donor. The measurable activity was strictly proportional to the amount of extract protein provided in the 


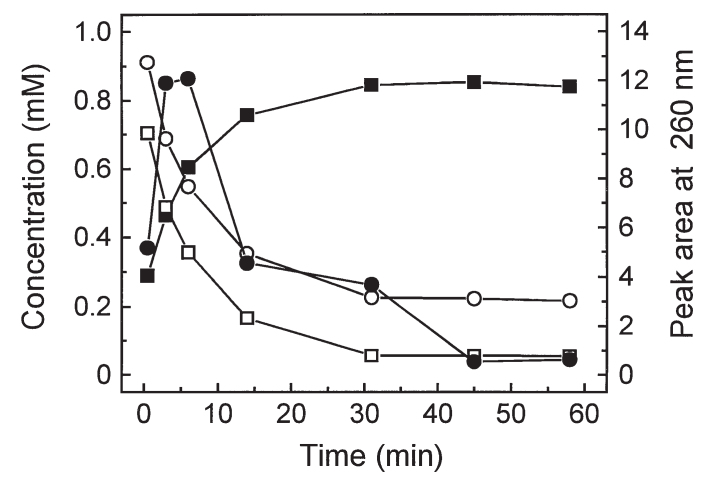

Fig. 1 HHQ reduction by cell-free extract of Desulfovibrio inopinatus. The assay contained $0.4 \mathrm{mg}$ cell-free extract, $0.8 \mathrm{mM}$ NADH $(\square)$ and $1 \mathrm{mM}$ HHQ $(O)$ at time zero. NAD ${ }^{+}(\square)$ and an unknown product eluting at $3.83 \mathrm{~min}(\mathbf{)})$ were formed. $\mathrm{NADH}$ and HHQ are shown at their respective concentrations, the unknown compound by its HPLC peak area

assay (results not shown). The specific activity was $0.25-$ $0.45 \mathrm{U}$ (mg protein $)^{-1}$, which is substantially higher than the metabolic activity of growing cells $\left[0.07 \mu \mathrm{mol} \mathrm{min}{ }^{-1}\right.$ $(\mathrm{mg} \text { protein })^{-1}$. When cells were grown with fructose or lactate, HHQ reductase activity was only $0.003 \mathrm{U}$ or $0.005 \mathrm{U}(\mathrm{mg} \text { protein })^{-1}$, respectively, indicating that this enzyme is not constitutively expressed. SDS-PAGE analysis revealed the presence of a $70-\mathrm{kDa}$ and a $45-\mathrm{kDa}$ protein band in a cell-free extract of HHQ-grown cells; these bands were absent in cell-free extracts of cells grown with fructose or lactate (results not shown). When cellfree extract was passed over a HiTrap Q anion exchange column, the $70-\mathrm{kDa}$ and the $45-\mathrm{kDa}$ protein band were both enriched (results not shown). The enzyme activity was localized nearly exclusively in the cytoplasmic fraction, which contained more than $80 \%$ of the total activity.

HHQ was stoichiometrically reduced with NADH to form $\mathrm{NAD}^{+}$and an unidentified reduction product (Fig. 1); the ratio of HHQ to NADH varied between 0.931 and 1.06. With NADPH as electron donor, the specific activity was $87 \%$ of that obtained with NADH. Other hydroxylated aromatic compounds such as catechol, resorcinol, hydroquinone, pyrogallol, phloroglucinol or 2,5-dihydroxyaniline were not reduced at significant rates.

Identification of the reaction product and its further degradation

When HHQ was reduced with NADH, small amounts of a product accumulated transiently during the first $10 \mathrm{~min}$ of the reaction (Fig. 1). This product shared properties with dihydrohydroxyhydroquinone, which was chemically produced from HHQ with sodium borohydride. The products of biochemical and chemical reduction both eluted from the HPLC column at 3.83 min (Fig. 2A, B), both compounds exhibited an absorption maximum at $260 \mathrm{~nm}$ (Fig. 2A-C), and both compounds had a mass of 127 when characterized as deprotonated mono-anions by mass
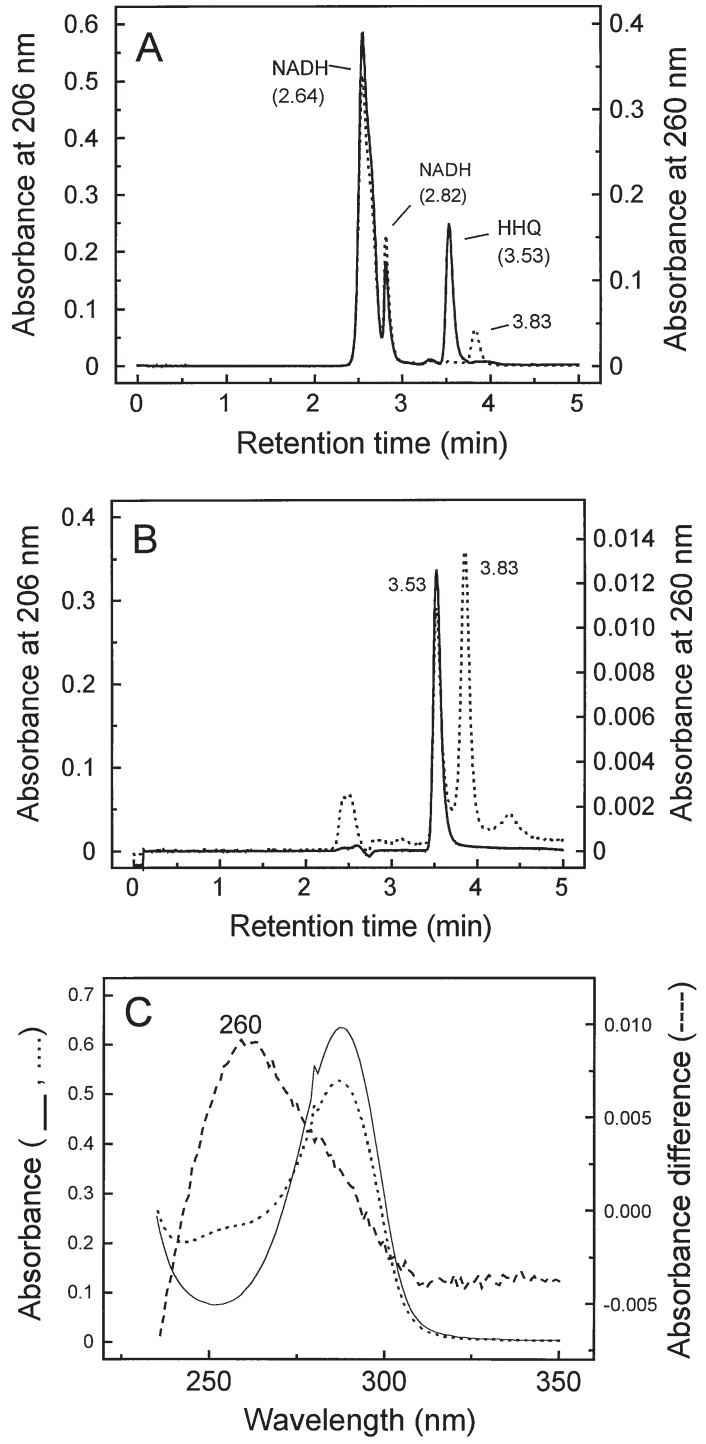

Fig. 2A-C HPLC Chromatograms and absorption spectra of the products of biochemical and chemical reduction of HHQ. The straight line was recorded at $206 \mathrm{~nm}$, the dotted line at $260 \mathrm{~nm}$ wavelength. A Chromatogram of a sample taken from the biochemical reaction after $14 \mathrm{~min}$. About $1 \mathrm{mM}$ HHQ was reduced with about $1 \mathrm{mM}$ NADH by $0.4 \mathrm{mg}$ cell-free extract. B Chromatogram of a sample withdrawn from the chemical reaction after $1 \mathrm{~h}$. The reduction was carried out by adding $1 \mathrm{mM}$ sodium borohydride dropwise to $1 \mathrm{mM}$ HHQ. Samples taken from both reactions were diluted five-fold prior to chromatography. C Absorption spectra of the chemical assay at time zero (solid line) and after $1 \mathrm{~h}$ (dotted line) and of the biochemically produced compound eluting at $3.83 \mathrm{~min}$ from the reversed phase column (dashed line). Spectra were recorded in ammonium phosphate buffer, $\mathrm{pH} 2.6$

spectroscopy (Fig. 3). These data, together with those on the reaction stoichiometry, allow the conclusion that dihydrohydroxyhydroquinone (1,2,4-trihydroxy 1,3 -cyclohexadiene) is the primary reduction product of the HHQ reductase reaction.

Dihydrohydroxyhydroquinone was not stable in cellfree extracts but reacted further (Fig. 1). Two more stable products were found that were formed mainly between 


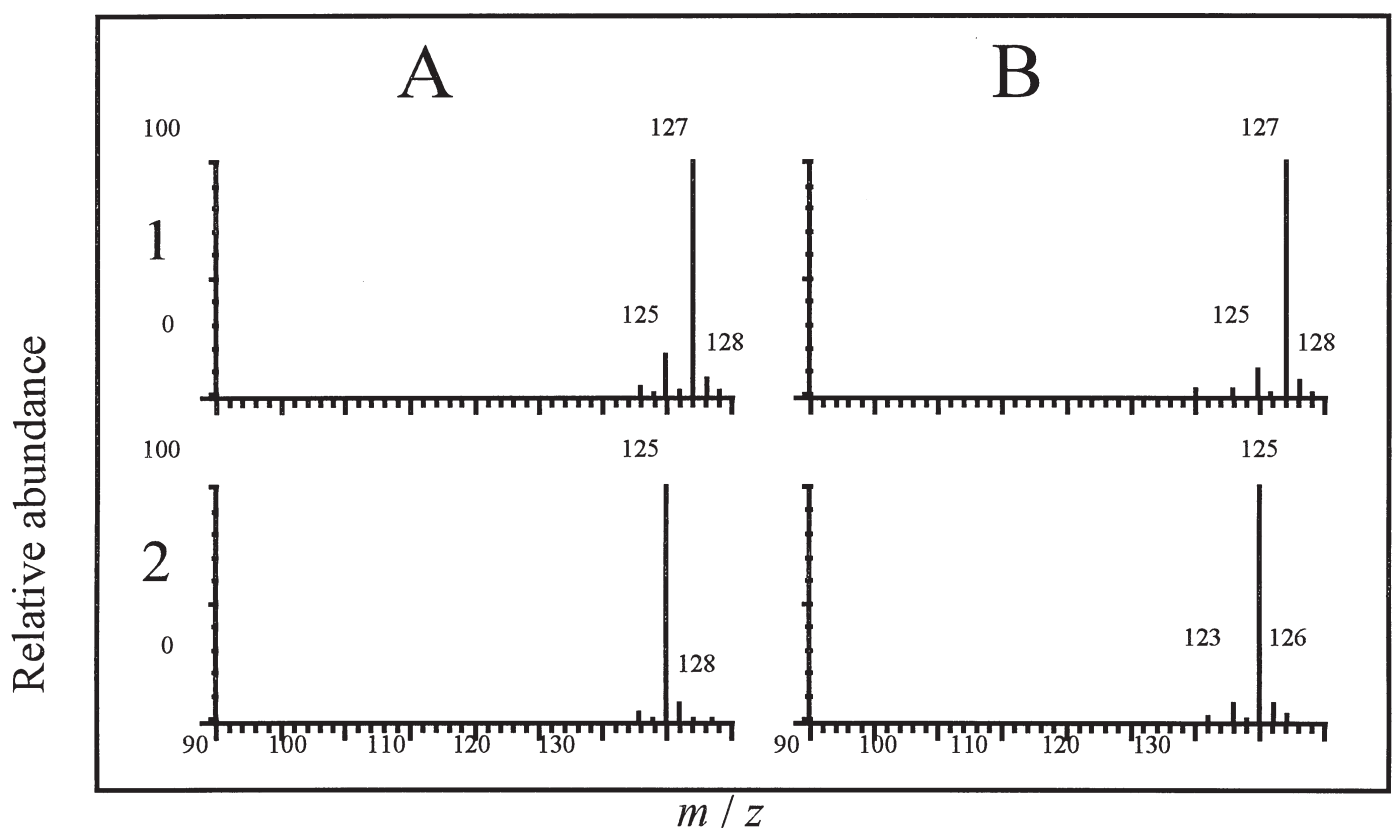

Fig.3 Negative-ion mass spectra of the product of biological (A) and chemical (B) HHQ reduction. The compounds were separated by HPLC prior to mass spectrometric analysis. Spectra $A I$ and $B I$ correspond to the reduction product with a mass of $127 \mathrm{Da}$, spectra $A 2$ and $B 2$ to HHQ

5 min and 15 min after start of the HHQ reductase reaction (Fig. 4A). One product was identified as acetate, which was formed stoichiometrically from HHQ at a 1:1 ratio. The second, so far unknown product appeared concomitant with acetate (Fig. 4A). It exhibited absorption peaks at 223 and $293 \mathrm{~nm}$ and a broader absorption band at $429 \mathrm{~nm}$ wavelength (Fig. 4B). HPLC comparison with an authentic reference compound indicated that this compound was not identical with succinate semialdehyde, which could be the coproduct of a hypothetical hydrolytic ring cleavage reaction.

\section{Reaction conditions and enzyme stability}

The dependence of the HHQ reductase activity on the prevailing $\mathrm{pH}$ was tested in a buffer mixture containing $25 \mathrm{mM}$ MES and $25 \mathrm{mM}$ MOPS. The activity exhibited a clear optimum between $\mathrm{pH} 7.2$ and 7.5, and dropped sharply at higher $\mathrm{pH}$ (not shown). Although $D$. inopinatus is a brackish water organism that grows optimally with $1 \% \mathrm{NaCl}$ in the medium, HHQ reductase activity was inhibited by the presence of $\mathrm{NaCl}$ in the assay, with $50 \%$ inhibition at $120 \mathrm{mM} \mathrm{NaCl}$ (not shown). $\mathrm{KCl}$ had a similar, $\left(\mathrm{NH}_{4}\right)_{2} \mathrm{SO}_{4}$ a lower inhibitory effect. HHQ reductase activity in cell-free extracts was comparably stable under air at $\mathrm{pH} 7.0$ or 6.0 , but was destroyed nearly completely during storage at $\mathrm{pH}$ 2.7. There was no significant difference in stability in the presence or absence of air oxygen. Surprisingly, the activity was less stable during storage on ice
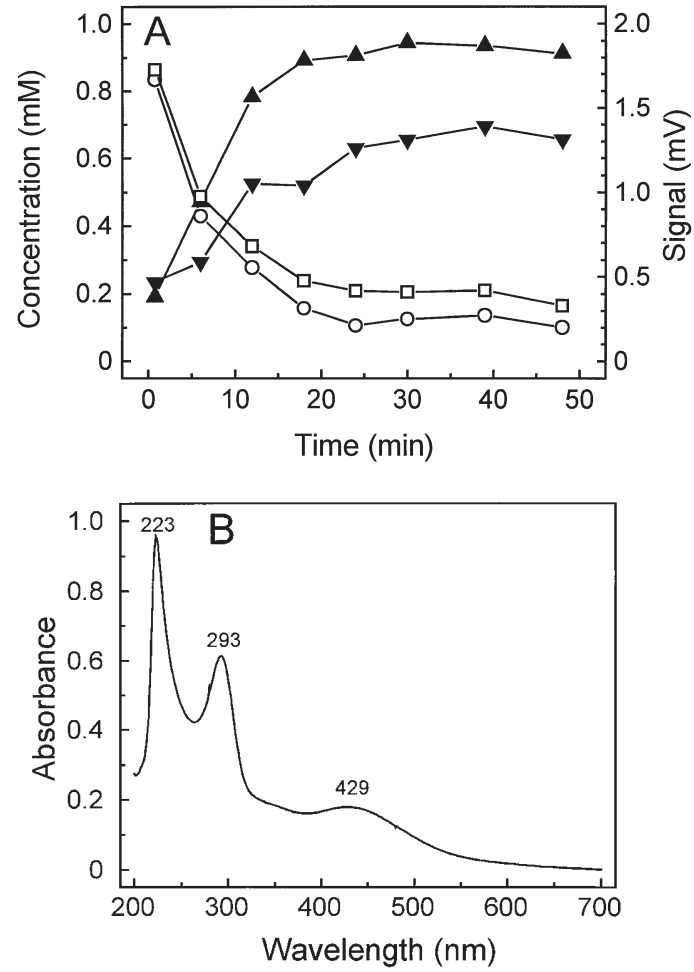

Fig. 4A,B Conversion of HHQ in cell-free extract of D. inopinatus and absorbance spectrum of one product. A Time course of the reaction showing the decrease of HHQ $(\bigcirc)$ and NADH $(\square)$ and the delayed formation of acetate $(\boldsymbol{\Delta})$ and an unknown product $(\boldsymbol{\nabla})$ eluting from the ion exchange column at 31 min retention time. B UV absorption spectrum of the unknown product. Fractions containing this compound were collected from the ion exchange column, lyophilized, and redissolved in $10 \mathrm{mM}$ acetic acid

than at room temperature; however, activity losses after cold incubation could be largely restored upon re-exposure to room temperature $\left(24^{\circ} \mathrm{C}\right.$; Fig. 5$)$. 


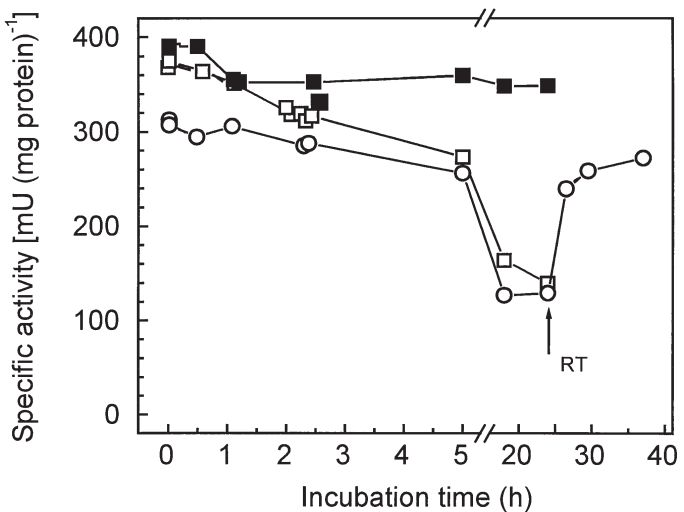

Fig. 5 Stability of HHQ reductase of D. inopinatus. Effect of temperature during incubation in $100 \mathrm{mM}$ potassium phosphate buffer, $\mathrm{pH} 7.0$, at different conditions. Cell-free extract was freshly prepared and kept anoxic at room temperature $\left(24^{\circ} \mathrm{C}\right)(\square)$, anoxic on ice $(\square)$, or under air on ice $(\bigcirc)$. The latter was set to room temperature after $24 \mathrm{~h}$ of incubation

HHQ-reductase was fairly stable to thermal denaturation and did not lose activity during $10 \mathrm{~min}$ incubation at $50^{\circ} \mathrm{C}$. At $60^{\circ} \mathrm{C}, 10 \mathrm{~min}$ incubation caused an activity loss of $50 \%$, and $5 \mathrm{~min}$ incubation at $95^{\circ} \mathrm{C}$ destroyed the activity entirely.

The enzyme activity was comparably stable towards inhibitors tested with other reductase enzymes (Table 1). There was little sensitivity towards $p$-chloromercuribenzoate and copper chloride, and iodoacetamide had no effect. EDTA caused a rather strong inactivation, with 50\% activity loss after $5 \mathrm{~min}$ of incubation with $0.2 \mathrm{mM}$ EDTA; $o$-phenanthroline acted in a similar manner. This inactivation pattern differs substantially from that of phloroglucinol reductase of E. oxidoreducens (Table 1).

\section{Discussion}

In the present communication, we report for the first time on an enzyme that destabilizes HHQ by a reduction reaction. This enzyme plays a key role in anaerobic HHQ degradation by $D$. inopinatus. Either NADH or NADPH could serve as electron donors in this reaction. Several fermenting bacteria employ NADPH as electron donor in reductive destabilization of the trihydroxybenzene isomer phloroglucinol (Samain et al. 1986; Haddock and Ferry 1989; Brune and Schink 1992). Although the two reactions initially appear to be similar, HHQ reductase differs substantially from phloroglucinol reductases, of which the enzyme of $E$. oxidoreducens has been described best (Haddock and Ferry 1989). Both enzymes are very specific for their respective substrate. They differ substantially with respect to inactivation by various compounds (see Table 1). Whereas HHQ reductase shows little sensitivity towards sulfhydryl reagents such as $p$-chloromercuribenzoate and copper chloride, phloroglucinol reductase is inactivated very strongly by these compounds. On the other hand, HHQ reductase is sensitive to EDTA and $o$-phenanthroline, which does not apply for phloroglucinol reductase. These results indicate that divalent cations such as $\mathrm{Fe}^{2+}$ may play an essential role in the reaction of HHQ reductase, whereas sulfhydryl groups appear not to be involved, and the opposite appears to be true for phloroglucinol reductase. Thus, although the catalyzed reactions appear to be similar, the reaction mechanisms might be substantially different.

In phloroglucinol, all hydroxyl groups are in meta-position to each other, which allows a tautomerization to a nonaromatic trioxo isomer and renders a reductive attack easy. Pyrogallol has all hydroxyl groups in ortho-position to each other and can be attacked preferentially by an oxygenase reaction, analogous to catechol; for anaerobic degradation of pyrogallol, a transformation to phlorogluci-

Table 1 Inactivation of HHQ reductase activity in cell-free extracts of Desulfovibrio inopinatus and of purified phloroglucinol reductase of Eubacterium oxidoreducens

\begin{tabular}{|c|c|c|c|c|c|c|}
\hline Compound & \multicolumn{3}{|c|}{ HHQ reductase ${ }^{\mathrm{a}}$} & \multicolumn{3}{|c|}{ Phloroglucinol reductase ${ }^{b}$} \\
\hline p-Chloro-mercuribenzoate & 1 & 20 & 69 & 0.1 & 5 & 0 \\
\hline $\mathrm{CuCl}_{2}$ & $\begin{array}{l}0.1 \\
0.1\end{array}$ & $\begin{array}{r}5 \\
30\end{array}$ & $\begin{array}{l}87 \\
88\end{array}$ & $\begin{array}{l}0.1 \\
0.001\end{array}$ & $\begin{array}{l}0.2 \\
0.2\end{array}$ & $\begin{array}{r}0 \\
57\end{array}$ \\
\hline EDTA & $\begin{array}{l}2 \\
0.2 \\
0.2\end{array}$ & $\begin{array}{r}30 \\
1 \\
5\end{array}$ & $\begin{array}{l}21 \\
79 \\
51\end{array}$ & 2 & 200 & 100 \\
\hline$o$-Phenanthroline & 0.5 & 5 & 16 & 10 & 200 & 68 \\
\hline
\end{tabular}

${ }^{\mathrm{a}}$ One milligram of cell-free extract was incubated at $24^{\circ} \mathrm{C}$ in

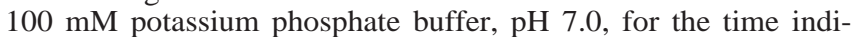
cated prior to activity assay. Enzyme assays contained $2 \mathrm{mM}$

HHQ, $0.3 \mathrm{mM} \mathrm{NADH}$, and $0.03 \mathrm{mg}$ crude extract. $100 \%$ activity equalled $109 \mathrm{mU}$ (mg protein $)^{-1}$

${ }^{b}$ Data taken from Haddock and Ferry (1989) 


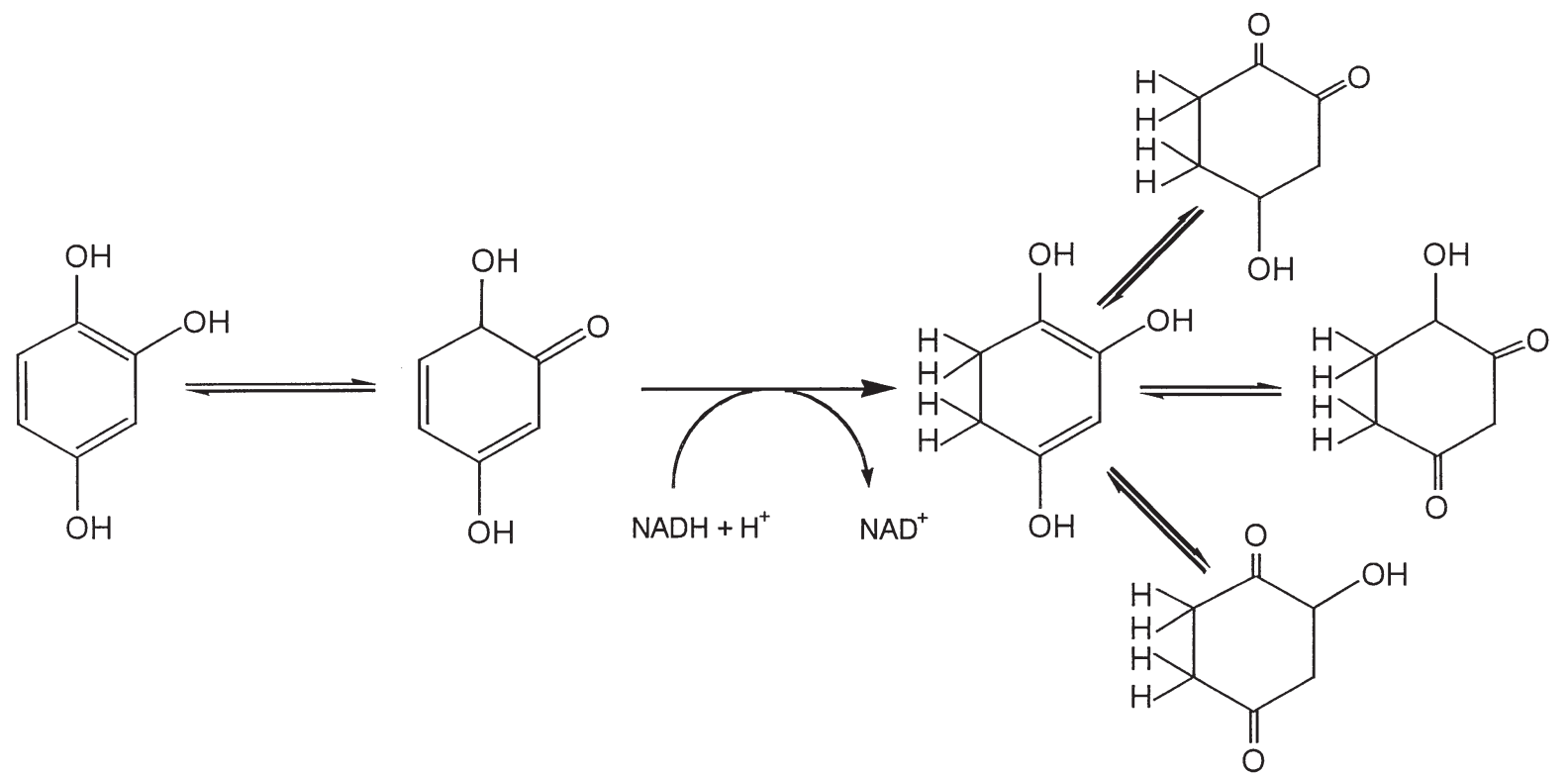

Fig. 6 HHQ reduction by HHQ reductase of D. inopinatus and tautomeric forms of dihydrohydroxyhydroquinone. Only one of the possible HHQ tautomers carrying a carbonyl group is shown

nol is required (Schink and Pfennig 1982; Brune and Schink 1990). HHQ carries hydroxyl groups in meta-position and in ortho-position to each other. The latter allows HHQ to be attacked by an oxygenase (Middelhoven 1993), and the former makes HHQ prone to direct reduction (this article). As a third alternative, HHQ is transformed to phloroglucinol, which is reduced afterwards (Brune et al. 1992). Obviously, the hydroxyl group in ortho-position does not prevent a reduction reaction that probably acts on the two hydroxyl groups in meta-position. Thus, the different chemistries of the trihydroxybenzene isomers HHQ and phloroglucinol might explain why different reductase enzymes with different reaction mechanisms are required.

The reduction of HHQ probably proceeds via reduction of a carbonylic group, analogous to other NADH-dependent reductase reactions. HHQ tautomers containing at least one carbonylic group can be formulated, and one of these tautomers has been suggested in the reaction scheme given in Fig. 6. The primary product of the HHQ reductase reaction was identified as dihydrohydroxyhydroquinone, a nonaromatic compound for which again several different tautomeric structures can be anticipated (Fig. 6). It is premature to speculate which structure may be prevalent; the form(s) prevailing in aqueous solution may be different from that on which the subsequent enzymatic cleavage reaction acts. The 1,3-dioxo tautomer of this aliphatic ring compound appears to be especially prone to a nucleophilic (thiolytic or hydrolytic) attack on carbon atoms 1 or 3, releasing an acetyl moiety and a four-carbon residue similar to succinate semialdehyde. The reaction product we found, together with acetate, was not identical with succinate semialdehyde, but it can be assumed that this rather unstable intermediate would quickly be further metabolized. The absorption spectrum of this compound indicates strong absorption maxima that might be attributed to double linkages; however, the identity of this compound is still open at the moment. Nonetheless, cleavage of the HHQ molecule to an acetyl residue and a four-carbon compound that might be metabolized to succinate is in accordance with the overall product pattern of HHQ degradation by $D$. inopinatus, provided that the four-carbon compound is further oxidized to one acetyl moiety, with concomitant transfer of the released electrons to sulfate reduction. The ring cleavage reaction will be subject to further study in our laboratory.

The HHQ reductase activity described in this communication initiates a further pathway of anaerobic HHQ degradation, which differs entirely from that used by the nitrate-reducing bacteria Azoarcus anaerobius (Philipp and Schink 1998) and Thauera aromatica (Gallus and Schink 1998). Whereas the nitrate reducers prepare HHQ ring cleavage by oxidation, $D$. inopinatus destabilizes the aromatic structure by a reductive step. With this, the strategy of $D$. inopinatus more nearly resembles the pathways of anaerobic degradation of aromatic compounds described so far, which all destabilize the aromatic ring by reduction (Schink et al. 1992; Fuchs et al. 1994; Heider and Fuchs 1997; Schink et al., in press). The new HHQ transformation reactions discovered recently add further details to the picture of anaerobic degradation of aromatic compounds, and broaden our view of the diversity of microbial metabolic capacities in general.

Acknowledgements This study was supported by the Deutsche Forschungsgemeinschaft, Bonn, Germany, in its special research program "Biochemistry of anaerobic bacteria", and by Fonds der Chemischen Industrie, Frankfurt/M. 


\section{References}

Armengaud J, Timmis KN, Wittich R-M (1999) A functional 4-hydroxysalicylate/hydroxyquinol degradative pathway gene cluster is linked to the initial dibenzo- $p$-dioxin pathway genes in Sphingomonas sp. strain RW1. J Bacteriol 181:3452-3461

Boll M, Albracht SSP, Fuchs G (1997) Benzoyl-CoA reductase (dearomatizing), a key enzyme of anaerobic aromatic metabolism. A study of adenosintriphosphatase activity, ATP stoichiometry of the reaction and EPR properties of the enzyme. Eur J Biochem 244:840-851

Bradford MM (1976) A rapid and sensitive method for the quantification of microgram quantities of protein utilizing the principle of protein-dye binding. Anal Biochem 72:248-254

Brune A, Schink B (1990) Pyrogallol-to-phloroglucinol conversion and other hydroxyl-transfer reactions catalyzed by cell extracts of Pelobacter acidigallici. J Bacteriol 172:1070-1076

Brune A, Schink B (1992) Phloroglucinol pathway in the strictly anaerobic Pelobacter acidigallici: fermentation of trihydroxybenzenes to acetate via triacetic acid. Arch Microbiol 157: 417-424

Brune A, Schnell S, Schink B (1992) Sequential transhydroxy lations converting hydroxyhydroquinone to phloroglucinol in the strictly anaerobic, fermentative bacterium Pelobacter massiliensis. Appl Environ Microbiol 58:1861-1868

Chapman PJ, Ribbons DW (1976) Metabolism of resorcinylic compounds by bacteria: alternative pathways for resorcinol catabolism in Pseudomonas putida. J Bacteriol 125:985-998

Fuchs G, Mohamed MES, Altenschmidt U, Koch J, Lack A, Brackmann R, Lochmeyer C, Oswald B (1994) Biochemistry of anaerobic biodegradation of aromatic compounds. In: Ratledge C (ed) Biochemistry of microbial degradation. Kluwer Academic, Dordrecht, pp 513-553

Gallus C, Schink B (1998) Anaerobic degradation of $\alpha$-resorcylate by Thauera aromatica strain AR-1 proceeds via oxidation and decarboxylation to hydroxyhydroquinone. Arch Microbiol 169: $333-338$

Haddock JD, Ferry JG (1989) Purification and properties of phloroglucinol reductase from Eubacterium oxidoreducens G-41. J Biol Chem 264:4423-4427

Heider J, Fuchs G (1997) Anaerobic metabolism of aromatic compounds. Eur J Biochem 243:577-96

Karasevich YN, Ivoilov VS, Oreshkin AE, Surovtseva EG (1976) Hydroxyhydroquinone as an intermediate compound in the preliminary metabolism of $p$-hydroxybenzoic acid in Candida tropicalis yeasts. Dokl Akad Nauk (Mosc) 229:735-737

Kluge C, Tschech A, Fuchs G (1990) Anaerobic metabolism of resorcylic acids ( $m$-dihydroxybenzoic acids) and resorcinol (1,3benzenediol) in a fermenting and in a denitrifying bacterium. Arch Microbiol 155:68-74
Kreft JU, Schink B (1993) Demethylation and degradation of phenylmethylethers by the sulfide-methylating homoacetogenic bacterium strain TMBS 4. Arch Microbiol 159:308-315

Krumholz LR, Bryant MP (1988) Characterization of the pyrogallol-phloroglucinol isomerase of Eubacterium oxidoreducens. J Bacteriol 170:2472-2479

Krumholz LR, Crawford RL, Hemling ME, Bryant MP (1987) Metabolism of gallate and phloroglucinol in Eubacterium oxidoreducens via 3-hydroxy-5-oxohexanoate. J Bacteriol 169: 1886-1890

Middelhoven WJ (1993) Catabolism of benzene compounds by ascomycetous and basidomycetous yeasts and yeast-like fungi. A literature review and an experimental approach. Antonie van Leeuwenhoek 63:125-144

Patel TR, Hameed N, Martin AM (1990) Initial steps of phloroglucinol metabolism in Penicillium simplicissimum. Arch Microbiol 153:438-443

Philipp B, Schink B (1998) Evidence of two oxidative reaction steps initiating anaerobic degradation of resorcinol (1,3-dihydroxybenzene) by the denitrifying bacterium Azoarcus anaerobius. J Bacteriol 180:3644-3649

Reichenbecher W, Schink B (1997) Desulfovibrio inopinatus sp. nov., a new sulfate-reducing bacterium that degrades hydroxyhydroquinone (1,2,4-trihydroxybenzene). Arch Microbiol 168 : 338-344

Samain E, Albagnac G, Dubourguier HC (1986) Initial steps of catabolism of trihydroxybenzenes in Pelobacter acidigallici. Arch Microbiol 144:242-244

Schink B, Pfennig N (1982) Fermentation of trihydroxybenzenes by Pelobacter acidigallici gen. nov. sp. nov., a new strictly anaerobic, non-spore forming bacterium. Arch Microbiol 133: 195-201

Schink B, Brune A, Schnell S (1992) Anaerobic degradation of aromatic compounds. In: Winkelmann $\mathrm{G}$ (ed) Microbial degradation of natural products. VCH, Weinheim, pp 219-242

Schink B, Philipp B, Müller J (in press) Anaerobic degradation of phenolic compounds. Naturwissenschaften

Schnell S, Brune A, Schink B (1991) Degradation of hydroxyhydroquinone by the strictly anaerobic fermenting bacterium Pelobacter massiliensis sp. nov. Arch Microbiol 155:511-516

Stolz A, Knackmuss H-J (1993) Degradation of 2,4-dihydroxybenzoate by Pseudomonas sp. BN9. FEMS Microbiol Lett 108: 219-224

Widdel F, Pfennig N (1981) Studies on dissimilatory sulfate-reducing bacteria that decompose fatty acids. I. Isolation of a new sulfate-reducer enriched with acetate from saline environments. Description of Desulfobacter postgatei gen. nov. sp. nov. Arch Microbiol 129:395-400 